\title{
Acerca de El español Gerardo: notas a la fecha, emulación y agustinismo de una novela barroca
}

\section{Concerning El español Gerardo: Notes to the Date, Emulation and Augustinism of a Baroque Novel}

\section{Julián González-Barrera}

Universidad de Sevilla

ESPAÑA

jgonbar@us.es

[Hipogrifo, (issn: 2328-1308), 8.2, 2020, pp. 665-685]

Recibido: 24-06-2020 / Aceptado: 29-07-2020

DOI: http://dx.doi.org/10.13035/H.2020.08.02.38

Resumen. En este artículo se examinan las causas que convertirían a El español Gerardo en un paradigma de la experimentación barroca, gracias especialmente al poderoso ascendente que ejerció el género bizantino. Una influencia que giraría en torno a la exégesis que hizo San Agustín acerca de la figura bíblica del peregrino, arquetipo convenientemente moldeado en este género del siglo XVII, así como su interpretación del papel de la Divina Providencia, que se recoge sobre todo en La ciudad de Dios.

Palabras clave. Gonzalo de Céspedes y Meneses; San Agustín; Biblia, novela bizantina; El español Gerardo; La ciudad de Dios.

Abstract. In this article, we examine the causes that made El español Gerardo an example of the baroque experimentation, thanks specially to the powerful influence of the Byzantine genre. An influence that spinned around the commentary of Saint Augustine about the biblical figure of the pilgrim, archetype convenientely molded in this genre in the XVIIth Century, as well as his interpretation of the role of the Divine Providence, as stated in the City of God.

Keywords. Gonzalo de Céspedes y Meneses; St. Augustine; Bible; Byzantine Novel; El español Gerardo; City of God. 
En cierta ocasión tratamos la Varia fortuna del soldado Píndaro (Lisboa, 1626) y las Historias peregrinas y ejemplares (Zaragoza, 1623), quedando fuera el Poema trágico del español Gerardo (Madrid, 1615)', acaso la más importante de las tres². Su autor, el talaverano ${ }^{3}$ Gonzalo de Céspedes y Meneses (1585-1638), fue uno de tantos escritores maltratados por la Historia, cuyo aplauso en vida fue inversamente proporcional a su fama póstuma. Historiador ${ }^{4}$, prosista y poeta, nos dejó como legado una narrativa notable que bien se merecía una nueva lectura ${ }^{5}$.

Las pruebas, causas y razones que convertirían a este libro en un paradigma de la experimentación barroca son dignas de atención, especialmente el poderoso ascendente que tuvo el componente bizantino en El español Gerardo. Una influencia que giraría en torno a la exégesis que hizo San Agustín acerca de la figura bíblica del peregrino, arquetipo convenientemente moldeado en este género del siglo XVII, así como su interpretación del papel de la Divina Providencia, que se recoge sobre todo en La ciudad de Dios. Un caso más de innovación de laboratorio que pondría a Céspedes bajo el pupilaje de Miguel de Cervantes o Lope de Vega en lo formal y del obispo de Hipona en lo sustancial. Un testimonio más de la aemulatio barroca que allanaría el camino hacia la consagración de la novela como el género supremo de la modernidad.

\section{LA FECHA}

Como consecuencia de su éxito editorial, el Poema trágico del español Gerardo y desengaño del amor lascivo tendría pronto una continuación en forma de segunda parte, a cargo de la imprenta de Sebastián de Cormellas (Barcelona, 1618). Una secuela que saldría a la venta unida a la primera, por lo que parece complicado que llegara a publicarse antes de manera independiente. Sobre esta posibilidad, Nicolás Antonio daba noticias de una misteriosa edición madrileña de 1617 que se anticiparía a la tirada barcelonesa ${ }^{6}$, pero sin dar más detalles. Por lo tanto, resulta muy

1. El libro está dedicado a don Gómez Suárez de Figueroa y Córdoba (1587-1634), duque de Feria y marqués de Villalba. Considerado como uno de los grandes generales de comienzos de siglo, tuvo una fulgurante carrera política y militar que se vería truncada antes de tiempo. Murió de tifus en la ciudad alemana de Múnich en plena Guerra de los Treinta Años.

2. Como prueba de su eco internacional valgan la temprana traducción al inglés a cargo de Leonard Digges, titulada Gerardo, the Unfortunate Spaniard or a Patterne for Lascivious Lovers (Londres, Ed Blount, 1622), y la italiana por Barezzo Barezzi de nombre Lo Spagnuolo Gerardo, Felice e Sfortunato (Venecia, Appresso il Barezzi, 1630).

3. Abraham Madroñal (1991) logró demostrar con solvencia que Céspedes nació en Talavera de la Reina y no en Madrid, como se creía, zanjando un viejo debate. Poco se sabe de sus relaciones personales; no obstante, en El español Gerardo hallamos algunos elogios a Vicente Espinel y Lope de Vega.

4. Como historiador escribiría la Historia apologética en los sucesos del reino de Aragón (Zaragoza, 1622), la Primera parte de la historia de don Felipe IV, Rey de las Españas (Lisboa, 1631) y Francia engañada, Francia defendida (Zaragoza, 1635).

5. Ver González-Barrera, 2009 y 2010.

6. Wilkinson y Ulla Lorenzo (eds.), 2016, vol. II, p. 273. 
difícil saber si podría tratarse de una reedición de la primera parte o la verdadera princeps de la segunda. A día de hoy está perdida?.

Sobre la posible fecha de composición aún existen dudas razonables, aunque a juzgar por las noticias aportadas por el propio autor, su hermano y algunos coetáneos, es muy probable que el talaverano empezara a escribir El español Gerardo en la cárcel. El motivo de su prisión es un verdadero enigma, si bien uno de sus editores modernos elucubraba con una «aventura amorosa» ${ }^{8}$.

A tenor de los datos internos que ofrece el texto, habría que situar el tempus scribendi más allá del 8 de abril de 1605, nacimiento del futuro Felipe IV, que quedaría como primer terminus post quem de la novela:

Corría en la ocasión de entonces la dichosa era y año de 605, en cuyo progreso nació a los 8 del mes de abril nuestro deseado y venturoso príncipe don Felipe, cuarto deste clarísimo nombre, con particular contento del Tercero, padre suyo?.

Una fecha que se podría recalibrar, en concreto más allá del regreso de la Corte a Madrid en 1606. Según las propias palabras de Céspedes, parece que «aquellos tiempos» de Felipe III en Valladolid habían quedado atrás en la memoria:

Era rama ilustre del antiguo y nobilísimo tronco de los caballeros Perafanes de Ribera, y natural de la real Sevilla, Babilonia de nuestra España, de adonde había salido a ciertas pretensiones para la ciudad de Valladolid, corte en aquellos tiempos de Felipe $1 I^{10}$.

Una pista clarividente a nuestro juicio, pues se corrobora en otros lugares del libro. Sin ir más lejos, apenas en la página siguiente, descubrimos que la alusión pretérita a Valladolid iría acompañada de una noticia de Madrid como residencia actual de los Reyes de España:

Mi nombre, ilustre amigo, es Gerardo; la insigne y famosa villa de Madrid, dignísimo aposento y morada de nuestros católicos monarcas, es mi amada patria, común y general madre de diversas gentes y remotas naciones ${ }^{11}$.

7. Si bien el taller estaba especializado en reimprimir los textos más comerciales, como bien nos recuerda el editor de Prolope: «La imprenta de Sebastián de Cormellas (padre) fue la más activa e importante de Barcelona en los años de 1591 a 1638 [...] Gracias a sus contactos con los más importantes impresores y libreros de la península, Cormellas siguió con atención el mercado literario español de aquellos años: de su taller en el Call salieron todo tipo de obras, especialmente los principales éxitos editados en la corona de Castilla» (en Lope de Vega, Comedias de Lope de Vega. Parte III, p. 31), sería precipitado aventurar que la edición barcelonesa no pudiese ser la princeps de la segunda parte.

8. Céspedes y Meneses, Historias peregrinas, ed. Fonquerne, p. 16.

9. Céspedes y Meneses, El español Gerardo, p. 146.

10. Céspedes y Meneses, El español Gerardo, p. 123.

11. Céspedes y Meneses, El español Gerardo, p. 124. 
Una comparación política entre el pasado y el presente que no parece producto del azar. Si bien es aconsejable la cautela, pues podría tratarse de un indicio prematuro, todo apuntaría a que el proceso de escritura habría terminado para entonces. En más de un pasaje de la novela se repite que la villa de Madrid era el Real Sitio: «que ya en esta coyuntura había días que, por gusto universal de sus majestades, grandes, títulos y consejeros, se había vuelto a su antiguo y mejorado asiento, noble y generosa villa de Madrid» ${ }^{12}$.

En El español Gerardo, el terminus post quem se podría arrastrar desde el 4 de marzo de 1606 - con la vuelta de la Corte- hasta el 20 de noviembre de 1610, cuando se rindió la ciudad de Larache a la infantería española comandada por el marqués de San Germán, en lo que había sido el segundo intento de asaltar la plaza tras el fracaso de una expedición en septiembre de 1608. ${ }^{13}$ En un momento determinado, el narrador recuerda una «primera jornada» de cuyo resultado prefiere no hablar - tal vez para no mentar la derrota-, pero que pondría en evidencia de que era muy consciente de que había habido más de un intento:

Tendría yo veinte años cuando, habiéndose movido la nobleza de España a servir en la primera jornada de Larache a nuestro poderoso monarca, incitado de amigos, y más del gusto de mis padres, con mucha voluntad suya, y bien lucido de armas, galas y criados, me hallé en ella. Tuvo el efeto que sabéis; y así... ${ }^{14}$

Por consiguiente, a finales de 1610 el talaverano aún estaría escribiendo la primera parte de El español Gerardo. Una novela que tuvo que terminar entre diciembre de aquel mismo año de 1610 y los últimos meses de 1614, pues la aprobación del doctor Gutierre de Cetina, la más temprana de las dos, está firmada el 11 de diciembre de 1614. Por este motivo es de suponer que, en noviembre, si no antes, Céspedes habría entregado ya el manuscrito al Consejo de Castilla para iniciar los trámites de impresión.

\section{LA EMULACIÓN}

Desde el mismo título, la obra pasaría por ser un relato autobiográfico ofrecido como escarmiento al lector. Una supuesta lección moral basada en desengaños «en parte verdaderos y en parte fingidos» ${ }^{15}$ - según se señala en el prólogo- que pondrían en cuarentena su carácter biográfico. Una justificación como la pretendida autobiografía que en todo caso no resultaría extraña al lector del Seiscientos, pues ya tenía sus antecedentes literarios en la picaresca o las memorias de soldado, con las que sin duda mejor emparentaría, dada la hidalguía del protagonista.

La discusión sobre la etiqueta que merecería una novela tan heterogénea como El español Gerardo ha hecho correr ríos de tinta. Una pléyade de juicios o hipóte-

12. Céspedes y Meneses, El español Gerardo, pp. 179-180

13. Ver el ejemplario ofrecido por López Enamorado, 2004.

14. Céspedes y Meneses, El español Gerardo, p. 166

15. Céspedes y Meneses, El español Gerardo, p. 118. 
sis que tendrían un denominador común: la imposibilidad de hallar un único adjetivo para calificar la narrativa del talaverano. Si atendemos a la opinión mayoritaria, convendríamos que se aprecia una mixtura desigual en sus páginas, donde se podrían rastrear rasgos de tradiciones distintas, a veces enfrentadas. Un texto híbrido donde se mezclarían la acción picaresca, el motivo bucólico, el argumento sentimental y por supuesto la novela bizantina o de peregrinos, como era conocida en aquellos tiempos ${ }^{16}$. En el caso concreto de la narrativa, además, se daban las condiciones ideales para el experimento. A pesar de la propagación comercial de la novela, apabullante en términos numéricos, lo cierto es que no suscitó mucho interés entre los preceptistas del Siglo de Oro, como el Pinciano, Cascales o González de Salas, que apenas le dedicaron una sola línea. Una de las consecuencias de no contar con una importante preceptiva, clásica o moderna, que sirviera de horma fue que la prosa de ficción fuera más permeable a otros géneros, como, por ejemplo, la comedia. En una de sus Novelas a Marcia Leonarda, Lope admitía las grandes similitudes que existían entre ambas: «Demás que yo he pensado que tienen las novelas los mismos preceptos que las comedias» ${ }^{17}$. Una comparación dirigida en concreto a la novela corta o italiana, que acabaría trasladándose con el tiempo a toda clase de narrativa. Esta apuesta creativa por desdibujar las fronteras será la base teórica de lo que se viene conociendo como metamorfosis de género, tan característica de la etapa barroca.

En consecuencia, como ya se explicó en su día ${ }^{18}$, Céspedes aprovechó esta oportunidad para recoger el guante lanzado por Cervantes y sondear una nueva clase de ficción encaminada a ocupar los ratos de ocio. Hace ya tiempo, Elide Pittarello fue una de las primeras en avisar del experimento formal de la prosa del talaverano y muy en particular de El español Gerardo:

[...] troviamo di fronte a una forma di narrazione per allora sperimentale, [...] derivata dalla fusione di modelli di scrittura diversi quali il romanzo bizantino, il romanzo caballeresco, il romanzo sentimentale e il genere pastorale ${ }^{19}$.

Una experimentación o mesa de trucos, que diría el manco de Lepanto, para recrear el eterno conflicto que plantea toda novela moderna: la lucha dialéctica entre el individuo y la sociedad. Las palabras de la estudiosa italiana no eran una afirmación inédita o solitaria. En realidad, pocos años antes, acerca de otra de las grandes obras del talaverano, Arsenio Pacheco ya se admiraba de la varietas de su narrativa. Una prueba más de la inspiración de don Gonzalo:

16. Incluso ha habido algún intento de vincular la obra con la mal Ilamada literatura fronteriza, tratándola como si fuera un género aparte (Hutchinson, 2016).

17. Lope de Vega, Novelas a Marcia Leonarda, p. 183.

18. González-Barrera, 2009, p. 762. No sería el único. Poco tiempo después, Giovanna Fiordaliso (2013) aceptaba el mismo punto de vista, reincidiendo sobre la influencia cervantina en Céspedes.

19. Pittarello, 1980, p. 44. 
En función de la tradición y de la historia literaria estas novelas están en deuda con la novela sentimental, con la novela bizantina y de aventuras y, sobre todo, con las novelas italianas, en las que es muy probable que Céspedes y Meneses hallara la inspiración de algunos episodios de sus propias novelas ${ }^{20}$.

Una estética de alambique donde afloraría la metamorfosis de género con el trasvase de elementos de la Comedia Nueva, por ejemplo, pero que destacaría sobre todo por el fuerte dominio de la materia bizantina ${ }^{21}$, como respaldaría la opinión general de la crítica: «El español Gerardo es una novela profundamente influida por la estética de las narraciones de Heliodoro y compañía, y el autor tal vez habría estado más acertado titulándola Trabajos y cautiverio del español Gerardo»22.

A medio camino entre la épica ${ }^{23}$ y la literatura de viajes, este género de la Antigüedad tardía aunaba dos anhelos en apariencia irreconciliables: el provecho moral y el entretenimiento profano. Lo bizantino se basaba en una estructura argumental simple, pero de desarrollo complejo, que tan brillantemente resumiera Zimic:

Toda novela bizantina es una historia de amor de dos jóvenes que por alguna razón muy urgente salen de casa y emprenden un viaje por tierra y mar, lleno de aventuras extraordinarias y peligrosas, que les exigen muchos sacrificios y les causan mucho sufrimiento. A menudo les obligan a separarse, aunque comúnmente hay un desenlace feliz, en forma de una reunión definitiva y un casamiento, premio de su constancia amorosa ${ }^{24}$.

Una deuda que no solo se explicaría por las similitudes de la trama con temas, motivos y técnicas bien documentados en aquellas novelas de aventuras, sino también por el contexto histórico como era aquel primer cuarto del siglo XVII, donde se había desarrollado un considerable entusiasmo por la prosa griega:

Heliodoro, y en menor medida, Aquiles Tacio, aparecen como autores de prestigio entre una minoría de creadores a lo largo de toda la Edad de Oro, aunque principalmente a partir de la segunda década del siglo XVII, tras las traducciones de ambas obras y las intervenciones de Lope de Vega y Cervantes en este sentido, que parecen actuar como incentivo para otros autores de sus círculos intelectuales. [...] En cualquier caso, la mayor parte de menciones e imitaciones de las novelas griegas está situada en un período de tiempo muy concreto, coincidiendo con la época de mayor número de reimpresiones de sus traducciones, lo que pa-

20. Céspedes y Meneses, Varia fortuna, p. LXVI.

21. En especial, la historia de amor entre Gerardo y Nise, la de mayor semejanza con el modelo bizantino. 22. Camamis, 1977, p. 158. Asimismo, Jenaro Tales la comparaba por las mismas razones con la Varia fortuna del soldado Píndaro, otra de las novelas de Céspedes: «Pero su estructura narrativa resulta más propia del género bizantino, como el Español Gerardo» (1977, p. 181).

23. Recuérdese la consideración de épica que le otorga el Tasso en sus Discorsi del poema eroico (1547): «Concedasi dunque che'l poema epico si possa formar di soggetto amoroso, com'è l'amor di Leandro e Hero, de' quali cantò Museo antichissimo poeta greco [...] o quelli di Teagene e di Cariclea, e di Leucippe e di Clitofonte, che nella medesima lingua furono scritti per Eliodoro e per Achille Tazio» (Tasso, Discorsi, p. 108)

24. Zimic, 2010, p. 28. 
rece confirmar de nuevo el carácter de moda que reviste la recepción de la novela clásica entre una élite intelectual ${ }^{25}$.

En la Edad Moderna, la invención de la imprenta había ocasionado la difusión masiva del texto escrito bajo una multitud de formatos: libro, cartilla, pliego, etc. La democratización del libro como bien de consumo puso en el centro del debate la responsabilidad del autor sobre su obra y los posibles efectos que las historias fingidas podían tener sobre los lectores, especialmente entre los más incrédulos o vulnerables. Dentro de aquella querella sin fin, la novela bizantina se erigió como una ocupación del ocio que contentaba tanto a lectores como moralistas. Por primera vez parecía posible un pasatiempo espiritualmente intachable para quienes rechazaban la literatura devota como entretenimiento. Siguiendo el oráculo de Aristóteles, Horacio y Cicerón, aquella narrativa de aventuras no solo conseguía entretener o admirar, sino también instruir una moralidad íntegra en torno a la defensa de la castidad. En definitiva, un paradigma de la deseada eutrapelia aristotélica o aquel otium cum dignitate que tanto celebrara el príncipe de los oradores ${ }^{26}$ y que estaba en el epicentro de la controversia ética en torno a los peligros de la ficción:

El ambiente exótico de palacios maravillosos, ciudades extranjeras y tierras lejanas, más las aventuras, trabajos y penalidades que padecían los protagonistas, aseguraban el deleite de los lectores mientras que la virtud de sus actos, la defensa inquebrantable de la castidad por parte de los amantes y la verosimilitud de sus argumentos, lograban adoctrinar con el beneplácito de los círculos religiosos y humanistas ${ }^{27}$.

El género bizantino consentía una vuelta a lo maravilloso preservando la necesaria verosimilitud. Tanto en la forma como en el contenido suponía la superación contrarreformista de los libros de caballerías. Una reconciliación estoica entre lo humano y lo divino que llegaba bendecida por las enseñanzas de Santo Tomás de Aquino, quien reafirmando lo dicho por el Estagirita, había proclamado la necesidad del juego o la diversión en la vida diaria:

Estos dichos o hechos, en los que no se busca sino el deleite del alma, se llaman diversiones o juegos. Por eso es necesario hacer uso de ellos de cuando en cuando para dar algo de descanso al alma. Esto es lo que dice el Filósofo en IV Ethic.: En la conservación de esta vida se necesita descansar mediante el juego. Hay que hacer uso de él, por tanto (Summa Theol. II-II, q. 168, a. 2.) ${ }^{28}$.

25. González Rovira, 1996, pp. 43-44.

26. Escribe Cicerón: «[...] sic, cum omnibus nobis in administranda re publica propositum esse debeat, id quod a me saepissime dictum est, cum dignitate otium, non idem semper dicere, sed idem semper spectare debemus» (Fam. I, 9, 21), que podríamos traducir como: «así, como todos nosotros debemos tener como objetivo combinar el ocio con la dignidad en nuestra vida pública, como he repetido frecuentemente, no deberíamos hablar siempre con las mismas palabras, sino tener siempre la misma meta». 27. González-Barrera, 2005, p. 78.

28. Santo Tomás de Aquino, Suma de Teología, IV, pp. 560-561. 
A principios del siglo XVII, muy pocos ingenios áureos fueron capaces de resistir la tentación de probar fortuna con la materia bizantina, fuera con una nueva novela de peregrinos o a través del uso puntual de motivos en cualquier otra de sus obras. El elogio, aprobación y reconocimiento por la historia de Teágenes y Cariclea se había extendido como la pólvora por todo el continente europeo. En España, incluso Alonso López Pinciano, tan poco interesado por la novela en general, considerará lo bizantino como una variedad de la épica ${ }^{29}$, situando a su principal autor como una autoridad superior a Homero en determinados aspectos. Era la constatación de un hecho. Heliodoro se había convertido en caza mayor para una generación que soñaba con superar a los clásicos algún día.

Heliodoro guardó eso más que ningún otro poeta, porque Homero no lo guardó con ese rigor, a lo menos en la llíada, ni aun en la Ulysea si bien se mira; y, si miramos a Virgilio, tampoco comenzó del medio ${ }^{30}$.

Los escritores barrocos de toda clase, origen y condición vivieron bajo el yugo de la aemulatio, acaso la mayor evolución teórica respecto a las posiciones renacentistas. Una nueva actitud artística conformada a partir de las corrientes italianas que habían cuestionado la mimesis aristotélica a lo largo del Quinientos (Gian Battista Guarini, Sperone Speroni, Gregorio Comanini, etc.), poniendo sobre la mesa un viejo debate que había arrancado la centuria anterior con humanistas como Leon Battista Alberti, que concibieron una mimesis basada en las leyes de la naturaleza y no tanto en la natura naturata, es decir, la apariencia de lo creado. A partir de entonces se sentarán las bases de una mimesis alternativa donde el arte irá ganando peso frente a la naturaleza, que ya no será considerada en su estado bruto, sino transformada por la voluntad del autor. Por consiguiente, el artista ganaba una libertad creativa desconocida hasta entonces. Una «natura vinta dall'arte» llegó a proclamar Giorgio Vasari al hablar de la obra de Miguel Ángel. El concepto de imitatio empieza a diluirse poco a poco hasta el punto de confundirse con la inventio. Alessandro Lionardi, discípulo de Speroni, escribía en su tratado Della inventione poetica:

Vi soviene appresso della Canzone del Petrarca, ove egli accusa Amore et poi nel difende? Et nel vero essendo lo scrivere poeticamente null'altro, che imitare le attioni de gli huomini, se il Poeta non si servisse ancora di questa guisa di parlare, sarebbe imperfetta la inventione, o imitatione che vogliam dire ${ }^{31}$.

29. Recuérdense las palabras del canónigo: «[...] que la épica tan bien puede escrebirse en prosa como en verso» (Cervantes, Don Quijote, p. 550).

30. López Pinciano, Philosophía antigua poética, pp. 482-483. En realidad, el Pinciano tendría en la cabeza las palabras de Julio César Escalígero en sus Poetices libri septem (1561), cuando colocaba a Heliodoro como el mejor modelo posible para los poetas épicos, como bien nos recuerda Julio Columbario en la Expostulatio Spongiae, aunque añada una salvaguarda para el autor de la llíada: «Escalígero propone como modelo de la épica a las Etiópicas de Heliodoro y, no obstante, Homero es el príncipe y gobierna sobre los poetas épicos» (González-Barrera, 2011, p. 311)

31. Lionardi, Della inventione, p. 30. Traducimos: «¿Os viene a la mente la Canción de Petrarca, donde acusa al Amor y luego lo defiende? Y si es verdad que el hecho de escribir poéticamente no es más que imitar las acciones de los hombres, si el poeta no se sirviese todavía de esta manera de hablar, sería imperfecta la invención, o imitación, que queremos decir» (muchas gracias a Serena Provenzano por su ayuda). 
Como resultado de este perfeccionamiento de la imitación ${ }^{32}$, la aemulatio surgirá como un mandato artístico que obligaba a poner a prueba la invención del autor, instándole a desafiar a los clásicos, si alcanzaba el ingenio. Una disposición del ánimo que nacería de la buena o sana envidia hacia estos grandes hombres. Una búsqueda de nuevas formas literarias que partiendo del modelo original (imitatio) pudiesen mejorar $\mathrm{y}$, por tanto, reemplazar a aquellos modelos o figuras de autoridad (aemulatio). En El héroe (1637), Baltasar Gracián animaba al hombre culto a la emulación como un camino directo a la fama, recordándole el ejemplo, inspiración y enseñanza de los grandes personajes de la Historia:

Carecieron por la mayor parte los héroes, ya de hijos, ya de hijos héroes; pero no de imitadores; que parece los expuso el cielo más para ejemplares del valor que para propagadores de la naturaleza.

Son los varones eminentes textos animados de la reputación, de quienes debe el varón culto tomar lecciones de grandeza, repitiendo sus hechos y construyendo sus hazañas.

Propóngase en cada predicamento los primeros, no tanto a la imitación cuanto a la emulación, no para seguirles, sí para adelantárseles.

Fue Aquiles heroico desvelo de Alejandro y, durmiendo en su sepulcro, despertó en él la emulación de su fama. Abrió los ojos el alentado macedón al llanto y al aprecio por igual, y lloró, no a Aquiles sepultado, sino a sí mismo, no bien nacido a la fama.

Empeñó después Alejandro a César, y lo que fue Aquiles para Alejandro, fue Alejandro para César; [...] Y nótese cómo se van heredando estos héroes con la emulación de la grandeza, y con la grandeza la fama ${ }^{33}$.

Volviendo a El español Gerardo, la intención de Céspedes por emular lo bizantino era más que evidente. No solo aquí, sino también en las Historias peregrinas y ejemplares, donde una falsa modestia disimularía la verdadera intención de competir con Heliodoro, Aquiles Tacio y otros:

[...] así también entre acciones tan graves ha producido maravillosa variedad de sujetos, que con acaecimientos peregrinos, no solo hoy lo son a mi pluma mas en otra mejor limada pudieran competir sus discursos, aun ceñidos al rigor de la historia, con los de Aquiles Tacio, decantado Heliodoro o con las ingeniosas sutiles del divino Ariosto $^{34}$.

Un desafío que, por cierto, en aquellas mismas fechas se planteaba el propio Cervantes con sus Trabajos de Persiles y Sigismunda, apenas dos años después de la publicación del Gerardo. Una voluntad meridiana que también se manifiesta de forma subrogada en la obra. En este caso no por boca del autor, sino por parte de una de las poetisas que rubrica los textos preliminares. En uno de los sonetos 
laudatorios, doña Beatriz de Zúñiga y Alarcón ${ }^{35}$ compara a don Gonzalo con el trágico cordobés - Séneca- y el mismísimo Heliodoro:

Y en urnas de diamante eternamente, vuestra memoria y vuestro nombre viva, trágico cordobés, griego Heliodoro ${ }^{36}$.

Como ya habían hecho Lope y otros ingenios áureos, Céspedes era consciente de que la renovación del género bizantino pasaba por un examen o adaptación de sus características principales al tiempo presente, es decir, a su época. No habría que olvidar que el punto de partida de la aemulatio fue siempre la imitación.

\section{LA EMULACIÓN (II): SIGUIENDO LOS PASOS DE HELIODORO}

Sin duda, el Gerardo fue un producto de su tiempo. Una novela híbrida o coral, moderna dirían algunos, donde se amalgamaron toda clase de temas, rasgos y argumentos tomados de aquí y de allá, pero admite poca discusión que el dominio de la materia bizantina sobre el resto es despótico. El poderoso influjo del autor de las Etiópicas se observa desde la primera línea, con un principio in medias res que sitúa el marco de la acción narrativa en un hallazgo fortuito, cuando tres pastores encuentran a un muchacho malherido en un bosque cerca de Segovia. Un misterioso caballero que será, por supuesto, el protagonista de la historia, Gerardo. Así comienza el libro:

Bramaba el aire, y con nublados negros a trechos matizaba el celestial color; y entre espesos relámpagos y temerosos truenos [...] hirió en las orejas de tres pastores rústicos que a la sazón unas ligeras cabras en ella apacentaban, una lastimosa y penetrable voz, de que quedaron tan confusos como temerosos, pareciéndoles hubiese salido de las entrañas y cavernosas partes de la tierra ${ }^{37}$.

Considerado como el estandarte del género, no tuvo que ser difícil para don Gonzalo elegir aquel ordo artificialis que tanto admiraba al lector, dejándole con la intriga de oír y entender lo que había sucedido antes ${ }^{38}$. En la novela bizantina española se empleó de forma extendida, antes y después de Céspedes, con la excepción quizás de las obras de Núñez de Reinoso y Contreras ${ }^{39}$.

35. Muy poco se sabe de esta dama, aunque algunos estudiosos apuntan a que podría estar emparentada con Juan Ruiz de Alarcón (King, 1989, p. 162).

36. Céspedes y Meneses, El español Gerardo, p. 118.

37. Céspedes y Meneses, El español Gerardo, p. 121.

38. Bastaría recordar cómo el Pinciano recomendaba a los poetas heroicos no comenzar por el principio, sino por el medio, en recuerdo de Heliodoro.

39. Clareo y Florisea de Alonso Núñez de Reinoso (Venecia, 1552) y La selva de aventuras de Jerónimo de Contreras (Barcelona, 1565), dos de los primeros paradigmas de la novela bizantina española. 
Una de las características de la prosa griega sería el motivo paradigmático del naufragio. La catástrofe retratada como la manifestación de un azar caprichoso que castiga a los enamorados con la separación. Un peligro que vendría de la mano de la tormenta, como alegoría de la fragilidad humana, donde los vientos y las olas se comportarían como instrumentos de aquel fatum terrible que maniobra en contra de los jóvenes amantes.

La función de este motivo es doble: por un lado, puede servir para producir la separación de los amantes, como vemos al principio del Peregrino lopesco; por otro, aparece como símbolo de la mutabilidad que amenaza la condición humana, proyectada en la inestabilidad marítima ${ }^{40}$

Camino de Argel, la galeota de Gerardo se ve inmersa en una violenta tormenta que la arrastra de nuevo hacia las costas de España. Cerca del cabo de Gata se topan de bruces con tres barcos de la Armada Real, que, confundiéndolos con piratas berberiscos, la hunden a cañonazos. A duras penas, Gerardo consigue ser rescatado junto a su amigo granadino, pero Jacinta se ahoga delante de sus ojos sin que pueda hacer nada por salvarla:

Con gran presteza intentó alejarse de los enemigos, los cuales ya venían en su seguimiento, adelantándose la Almiranta, que era uno dellos; mas viendo que se les iba la presa, como dicen, de entre las uñas, disparando las dos piezas de la amura, quiso el cielo acertasen a dar por tan buena parte a la pobre galeota, que, como de borrasca y continuos golpes de mar viniese por muchos lugares sentida, en un pensamiento se vio el gran daño que los tiros y balas en ella hicieron; porque le empezó a entrar tanta agua y con tanta furia, que sin que las voces y alaridos que daban, ni el socorro que a los contrarios galeones pedían, pudiese llegar a coyuntura, en un momento se fue a pique, pereciendo casi cuantos iban dentro [...] viendo a sus ojos, sin poderla remediar, perderse o negarse aquella que tan ardientemente había amado y querido ${ }^{41}$.

Recurrente en todo relato bizantino, el recurso a la anagnórisis -o reconocimiento, que diría el Pinciano - era una herencia directa de la tragedia griega que se usaba para aumentar la admiratio en el lector. Una técnica especialmente indicada en momentos de gran tensión dramática, donde el héroe debe renunciar a la protección del anonimato y revelar su verdadero nombre u origen, ya sea ante sus aliados o enemigos. Una desnudez simbólica que los deja a merced del resto de personajes, para bien o para mal, por lo que suele marcar importantes puntos de inflexión en la historia o incluso el final de la misma. En El español Gerardo, el travestismo de identidad es harto frecuente, por lo que muchos entran y salen de la acción bajo distintos nombres, atuendos y creencias.

Una cadena bastante frecuente consistía en unir la anagnórisis al motivo de la falsa muerte, incrementándose aún más el dramatismo de la escena. En realidad, se trataría de facto de una variante del deus ex machina, tan grato para el lector 
ávido de sorpresas. Gerardo descubre su identidad a Sanabria, el criado de su hermano, que lloraba su muerte mientras tres pastores eran llevados al cadalso injustamente acusados de su asesinato:

[...] dándolos cruelísimos tormentos [...] todos tres confesaron de plano cuanto se les pedía [...] y llevándolos por las calles al lugar del suplicio [...] conocido del herido Gerardo su querido siervo Sanabria, espantado de verle hacer tan increíble Ilanto, mandó a un criado que saliese a llamarle con la brevedad que su deseo pedía; que como semejante razón oyese el afligido mozo, y asimismo conociendo la voz de Gerardo levantase la cabeza, reconociéndole en la reja adonde estaba, abiertos los ojos, sin mover pie ni mano, cual arrobado en éxtasis, se quedó admirado y suspenso ${ }^{42}$

Asimismo, El español Gerardo presenta también motivos o técnicas que se habían introducido en el género poco tiempo atrás, lo que evidenciaría que Céspedes manejaba, conocía y participaba de lo contemporáneo. Es el caso, por ejemplo, de los ermitaños que de vez en cuando se cruzan en el camino de los protagonistas. Sus largos discursos rebosantes de arrepentimiento orientan las decisiones de los enamorados desde una perspectiva estoica, encontrando a veces el aviso o respuesta a sus dilemas morales. Son personajes que suelen presentar antecedentes similares: viven fuera de la sociedad por decisión propia, pues tratan de expiar algún pecado sirviendo de exemplum ad contrarium para todo aquel que quiera escucharles. Es el caso de Roberto, cuya trágica historia se cuenta en el segundo discurso, quien a la postre solo, afligido y lleno de remordimientos decide convertirse en peregrino para pagar por la muerte de su esposa Isdaura.

No cabe duda de que estamos ante un motivo literario que tendría su origen en II libro del Peregrino (1508) de Giacomo Caviceo, que había sido traducido por Hernando Díaz en 1520 bajo otro título -El peregrino y Ginebra-, y de cuya autoría se intentó apropiar, todo sea dicho. Gracias a esta obra, que a su vez bebe de II Filocolo de Boccaccio, se producirá un paso adelante decisivo en la novela sentimental hacia lo que más tarde se conocerá como novela bizantina barroca o de peregrinos, con la inclusión de un tono general de desengaño, así como el propósito moralizante o ascético que inspiraba este tipo de personaje ${ }^{43}$. A la salida del puerto de Fuenfrida, Gerardo, Leriano y Leoncio se topan con una extraña salvaje, a la que siguen hasta una cueva, pensando en un primer momento que podría ser un animal. Una vez descubierta su condición de mujer, la ermitaña les cuenta su triste vida pasada: su nombre es Leonora y vive apartada del mundo después de haber sido descubierta en fragrante adulterio con el hijo de su marido. Conmocionados por la historia, prometen pagarle la dote para entrar en un convento, pero ella prefiere huir y regresar al bosque para seguir pagando por sus pecados ${ }^{44}$.

42. Céspedes y Meneses, El español Gerardo, p. 140.

43. Vilanova, 1989, p. 337.

44. El episodio de Leonora se puede leer hacia el final del primer discurso (Céspedes y Meneses, El español Gerardo, pp. 140-143). 
Sin temor a equivocarnos, se podría afirmar que la presencia de estos eremitas entroncaría El español Gerardo con otros títulos contemporáneos de la tradición bizantina, como la Selva de aventuras de Jerónimo de Contreras (1565), donde ciertos pasajes están inspirados claramente en Caviceo, o El peregrino en su patria lopesco (1604), que el autor admitía conocer de primera mano:

No me escribió Belardo; que no implora

mi autor laureles a su patria ingrata,

premio por bien llorado merecido 45 .

Uno de los pocos argumentos del género que el libro parece eludir sería el anhelado final feliz. Un desenlace prototípico que no se ejecutará a la manera habitual por medio del matrimonio, sino bajo el prisma dogmático de la Contrarreforma, que vertebra toda la novela bizantina barroca, antes y después de la obra de don Gonzalo. Las malas experiencias provocarán el deseo de enmienda en los personajes principales, incluida la renuncia al amor. Una conclusión que no nos puede resultar del todo ajena, pues el arrepentimiento, resignación y penitencia ante los avatares de la vida era un final conocido en las novelas herederas de Heliodoro:

Hay que tener en cuenta que el retiro a un monasterio por parte de los protagonistas es una tipología de final que está presente en dos de las obras fundacionales del género: el retiro de Isea en el Clareo y la vida monástica en la Selva de aventuras de $1565^{46}$.

La existencia humana entendida, por tanto, como un camino tortuoso hacia la sabiduría por medio del aprendizaje. Una peregrinación que simbolizaría el vano afán del hombre por buscar la felicidad. En clave estoica, el final de El español Gerardo nos recordaría la insignificancia de la vida terrenal y el valor de la sabiduría como la defensa más eficaz contra los golpes del destino. Esta idea de la educación a través del viaje y la experiencia conformaría el epítome del alma barroca -homo viator-, cansada del idealismo de los libros de caballerías. Una cantidad importante de ingenios áureos reafirmaron esta noción en sus obras (Saavedra Fajardo, Suárez de Figueroa, Salas Barbadillo, Quevedo, etc.), reiterando el mismo sentir, pero quizás no hubo mejor elucidación que la prosa de Baltasar Gracián:

[...] fue gustoso peregrino; segunda felicidad para un hombre de curiosidad y buena nota [...] Adquiérese aquella ciencia experimental, tan estimada de los sabios, especialmente cuando el que registra atiende y sabe reparar, examinándolo todo o con admiración o con desengaño [...] La misma Filosofía no es otro que meditación de la muerte; que es menester meditarla muchas veces antes, para acertarla hacer bien una sola después ${ }^{47}$. 
La enumeración de los elementos bizantinos se podría extender aún más a otras características como la suspensión, el cautiverio, la analepsis completiva, las historias interpoladas, etc., pero vendríamos a reiterar lo ya establecido. Así, el Gerardo no sería una novela bizantina stricto sensu, sino más bien una miscelánea coral compuesta de diversos géneros, pero el peso neto de esta tradición sería muy superior al resto.

\section{EL AGUSTINISMO}

Una de las mejores demostraciones de que la narrativa de Céspedes estaría aun más próxima a la novela barroca de peregrinos que al molde clásico sería el rol decisivo que jugará la Divina Providencia en el desarrollo de la trama. En momentos determinados parece advertir a Gerardo de lo que puede llegar a pasar si desatiende sus señales. Unos avisos del cielo que adoptaban la forma de una «negra y horrible sombra», en palabras del narrador:

[...] no cesando de dar al cielo gracias por haberle librado de su peligro, de quien aun mucho antes (si bien Gerardo no acertó a entenderlo) su inefable sabiduría le había prevenido y avisado; porque, ¿qué otra cosa podemos imaginar de aquel espantoso temor, negra y horrible sombra, de quien primero se vio tan afligido, sino que fuese particular golpe y aviso de su maravillosa providencia para que, compungido en él, conociese Gerardo el tenebroso abismo por donde a tan grandes peligros se acercaba? ${ }^{48}$.

La apuesta de algunos investigadores por vincularla estrechamente a la antigua prosa griega nos parece desacertada ${ }^{49}$. Nunca existió a decir verdad una completa sinonimia entre providencia cristiana y hado pagano ${ }^{50}$. En realidad, esta novela habría que situarla en el contexto histórico del debate contrarreformista acerca de la predestinación y el libre albedrío, peligrosamente inflamado por la popularidad de la astrología judiciaria ${ }^{51}$ y que estaría en la epicentro de la polémica de auxiliis entre jesuitas y dominicos (1582-1607). Una controversia que todavía coleaba, pues se había cerrado en falso por orden papal pocos años antes de escribirse el Gerardo52.

48. Céspedes y Meneses, El español Gerardo, p. 218.

49. «Por ello, a pesar de que el tema de la Providencia comulgue a la perfección con el espíritu contrarreformista, hay que tener en cuenta que también enlaza directamente con la importancia que se le concede a la religión y a la divinidad en la novela heliodoriana. Por ello nos es posible afirmar que el tema de la Providencia pudo ser una herencia de la novela griega, especialmente de Heliodoro» (Cucala Benítez, 2006, p. 342).

50. En 1570, Antonio de Torquemada ya establecía las diferencias entre fortuna, hado y providencia en el tratado cuarto de su Jardín de flores curiosas (pp. 332-362).

51. «[...] algunos postulados espinosos de la astrología judiciaria [...] comprometían la influencia de signos, planetas y estrellas en el destino de los hombres, un vestigio del pagano fatum que colisionaba con el libre albedrío cristiano» (González-Barrera, 2018, p. 320).

52. A decir verdad, aquel 28 de agosto de 1607 el papa Paulo V decidió prohibir cualquier debate sobre la gracia, otorgando libertad de doctrina tanto a jesuitas como dominicos. Aquella solución salomónica no acallaría el debate público, mucho menos en la literatura, donde la predestinación escrita en las estrellas había echado raíces como locus communis 
Aquellos largos viajes en los que se embarca el protagonista, repletos de aventuras, infortunios y trabajos serían el testimonio literario del penoso peregrinaje del hombre por este valle de lágrimas ${ }^{53}$. Una creencia escatológica inspirada en multitud de pasajes de la Biblia (Gen 12, 10; Sal 119, 19; Heb 11, 13; 2Cor 5, 6-8, etc.), que había adquirido una especial trascendencia a finales del siglo anterior como alegoría de la condición humana. En su lucha contra el fatalismo protestante, la Iglesia católica favoreció el advenimiento de un nuevo modelo de cristiano: el peregrino.

El constante vagar de la existencia nómada, la errante peregrinación sobre la tierra de los hijos de Abraham, desemboca en la creencia de que la vida no es más que un transitorio peregrinaje. Así este se convierte en símbolo de la vida humana, en la imagen perfecta de la condición del hombre en su paso por la tierra ${ }^{54}$.

Un hombre consciente de que su tiempo en la tierra no era más que un angustioso destierro lejos de Dios. Un vagabundear por los caminos del mundo que debía servirle como aprendizaje y, por tanto, preparación para lograr la gloria de la vida eterna. Hasta el punto de que la ortodoxia contrarreformista pondrá en valor la respuesta de Jacob al Faraón, cuando equipara años vividos con tiempo peregrinado:

Y dijo Faraón a Jacob: ¿Cuántos son los días de los años de tu vida? Y Jacob respondió a Faraón: Los días de los años de mi peregrinación son ciento treinta años; pocos y malos han sido los días de los años de mi vida, y no han llegado a los días de los años de la vida de mis padres en los días de su peregrinación (Gen 47, 8-9).

Por consiguiente, para el pensamiento católico vivir y peregrinar se convertirán en lo mismo. No nos puede extrañar entonces que al final de la novela Gerardo aprenda de sus desdichas que lo verdaderamente sustancial no reside en la búsqueda de la felicidad a través del amor mundano, sino en la asimilación del alma con Dios, como indicara Boecio ${ }^{55}$.

Para entender este concepto de peregrino que aflora en las páginas de El español Gerardo, habría que remontarse más de mil años atrás, cuando la Patrística lo desarrolla como doctrina gracias sobre todo a la Ciudad de Dios de San Agustín (siglo V d. C.) $)^{56}$. Para el obispo de Hipona, la vida sería una peregrinatio aerumnosa, es decir, un amargo camino de perfeccionamiento espiritual que puede que nunca llegue a completarse del todo, quedando en el aire la meta última de aquel tránsito: la salvación del alma. En una de las traducciones de la Ciudad de Dios de principios

53. «Bienaventurado el hombre que tiene en ti sus fuerzas, en cuyo corazón están tus caminos. Atravesando el valle de lágrimas lo cambian en fuente cuando la lluvia llena los estanques» (Sal 84, 5-6). 54. Vilanova, 1989, p. 333.

55. «[...] nam quoniam beatitudinis adeptione fiunt homines beati, beatitudo vero est ipsa divinitas, divinitatis adeptione beatos fieri manifestum est» (Boeth., Cons. Phil. III, 10, 23).

56. Véase el excelente artículo de Claussen (1991) sobre las diferentes interpretaciones de la palabra peregrino en el mundo antiguo y los problemas de traducción que ocasionaron a San Jerónimo y otros exégetas bíblicos. 
del Seiscientos (1614), quién sabe si conocida por Céspedes, se describe al cristiano como un peregrino elegido por la Gracia divina:

El que es peregrino en este siglo y el que pertenece a la ciudad de Dios, predestinado por la gracia, elegido por la gracia y por la gracia peregrino acá en la tierra; y por la gracia ciudadano allá en el cielo57.

La misma dimensión teológica que vertebra el libro, cuando Gerardo parece estar protegido por la Providencia, que en forma de «negra y horrible sombra» le avisa y advierte de los peligros de sus decisiones. Como le sucede al protagonista, San Agustín nos recuerda que el cristiano está siempre acompañado por la Gracia de Dios. El único matiz reseñable sería que Gerardo pertenece a una clase particular de peregrino que surge como una adaptación novelesca del arquetipo religioso. La materia bizantina le dará el protagonismo a aquel que recorría el mundo en busca de una felicidad nacida de la idealización platónica del sentimiento amoroso: el peregrino de amor.

Este casto peregrinaje de los dos amantes, consumidos por la más violenta pasión, aferrados a la virtud contra todas las asechanzas y trabajos que les depara la Fortuna, contiene una idea ascética de purificación por el sufrimiento que hará suya la novela de la Contrarreforma ${ }^{58}$.

En nuestra opinión, será precisamente el quebranto de la castidad lo que abocará a Gerardo al desengaño, de ahí que no haya una única protagonista femenina en la novela, sino varias. El reconocimiento de la derrota por no haber sido capaz de someter las pasiones del alma, cultivando la virtud interior, cerraría el círculo católico de pecado, culpa y arrepentimiento que el autor nos expone como aviso al lector.

La razón estribaría en que la evolución literaria de este paradigma cristiano se empleaba como correa de transmisión de los dogmas de la Contrarreforma. No sólo en el caso de Céspedes. Legatario directo del peregrino medieval, que deambulaba por Tierra Santa para ganarse el perdón de sus pecados, este héroe sin hábito ni túnica se comportará como un caballero errante por un camino de servidumbre bajo la égida del omnia vincit amor ${ }^{59}$. Una figura que será continuamente puesta a prueba por medio de un sempiterno conflicto interior, donde los sentimientos opuestos se enfrentan por el dominio del alma.

[doña Clara] trocó [...] el amor y voluntad con que hasta entonces había amado en mortal odio y aborrecimiento, y aun más crecido (porque siempre se aborrece con mayor violencia de lo que se quiso) ${ }^{60}$.

57. San Agustín, La ciudad de Dios, p. 417.

58. Vilanova, 1989, p. 354.

59. «por eso pintan ciego y niño al poderoso amor, que como tal no piensa ni repara en ningún grande o pequeño inconveniente: todos los atropella y deshace, hasta vencer sus dificultades o despeñar a los que le siguen» (Céspedes y Meneses, El español Gerardo, p. 134)

60. Céspedes y Meneses, El español Gerardo, p. 145. 
Una colisión de fuerzas entre amor y odio que, por cierto, ya se había planteado Santo Tomás de Aquino, inspirándose en las enseñanzas del obispo de Hipona, aunque en verdad lo que planteaba el dominico sería una interpretación libérrima de las Ochenta y tres cuestiones diversas. San Agustín no se ocupó propiamente del tema:

En efecto, dice San Agustín en el libro Octoginta trium quaest.: Nadie hay que no huya del dolor más que apetezca el deleite. Pero huir del dolor pertenece al odio, mientras que el apetito del deleite pertenece al amor. Luego el odio es más fuerte que el amor [...] Solución. Hay que decir: Es imposible que el efecto sea más fuerte que la causa. Ahora bien, todo odio procede de algún amor como de causa, según se ha dicho anteriormente (a.2). Por lo tanto, es imposible que el odio sea absolutamente más fuerte que el amor (Summa Theol. I-II, q. 29, a.3) ${ }^{61}$.

En conclusión, el peregrino se constituirá en un contrapeso sublimado a las figuras del pastor y el pícaro, inanes en la lucha contra el credo protestante. Aquella profunda cristianización del modelo bizantino había pergeñado un nuevo arquetipo novelesco más próximo a la moralidad católica que cualquier otro hasta la fecha:

Así como el caballero andante es el ideal heroico del mundo medieval, y el cortesano el arquetipo ejemplar de hombre del Renacimiento, el peregrino es el paradigma del hombre del Barroco y el ideal del caballero cristiano ${ }^{62}$.

Por lo tanto, parece claro que la intervención de la Divina Providencia en la cabeza de Gerardo no sería una herencia directa de Heliodoro o Aquiles Tacio, sino de la novela bizantina barroca o de peregrinos, que había surgido a finales del siglo XVI y que estaba tan de moda en aquel primer cuarto del siglo XVII. En la obra de Céspedes, la providencia guía, influye, pero no decide, tal y como predicaba la Compañía de Jesús. Según la postura jesuítica, defendida sobre todo por el padre Luis de Molina (1535-1600), Dios predestina al hombre a causa del buen uso previsto de su libre albedrío. Recuérdense las últimas palabras de Gerardo:

Y digo que ya la divina Providencia, a quien nada se encubre, lo sabía, y no obstante que yo vivía seguro del inundoso mar, dispuso su voluntad y corazón a tan buena elección de que colijo que es lo más conveniente y necesario a nuestras almas su estado venturoso, a quien el mío procurará seguir, dándome su favor y ayuda el cielo, en quien firmemente confío63.

Sin ánimo de reabrir aquí la vieja controversia de auxiliis, convendría recordar el valor que posee el libre albedrío en la fe católica como uno de los mayores regalos de Dios a la Humanidad. Un dogma transcendental antes y ahora, pero mucho más en aquellos tiempos de la Contrarreforma, cuando se contendía con el determinismo protestante en púlpitos, cátedras y salones. Para el obispo de Hipona, la acción de la gracia divina no suprime la libertad del hombre en aquel amargo peregrinaje,

61. Santo Tomás de Aquino, Suma de Teología, II, p. 261.

62. Vilanova, 1989, p. 332.

63. Céspedes y Meneses, El español Gerardo, p. 270. 
puesto que la salvación del alma depende de sus propias decisiones. El tránsito hacia la otra vida estaría lleno de pruebas encaminadas a ir transformando poco a poco lo malo en bueno, es decir, a purificar el alma:

Primero es lo réprobo y malo, de donde es fuerza que comencemos y en donde no es menester que nos quedemos. Y después es lo bueno, adonde aprovechando caminemos y adonde llegando nos quedemos. Por lo cual, aunque no todo hombre malo será bueno, con todo ninguno será bueno que no haya sido malo64.

Como le ocurriera al mismo San Agustín, Gerardo tendrá la oportunidad de rectificar su vida pasada, atendiendo los avisos del cielo y enmendando sus errores. Solo el más ingrato o insensato desatendería a la gracia divina, pero a la postre siempre será su decisión. Al final de la obra, Gerardo se despide de sus familiares y amigos, abrazando el servicio a Dios:

Os suplico que, reconociendo en la memoria de mi pasada vida sus acaecimientos y peligros espantosos, consideréis juntamente los maravillosos medios y caminos que para remediarme y librarme dellos ha usado la bondad y misericordia infinita de Dios, a quien, según esto, no solo vengo a deber las principales obligaciones que las demás criaturas redimidas con su sangre, sino todas las accesorias y singulares en quien yo por mis pecados he caído y su inmensa piedad me ha levantado. Quede asentada como testimonio infalible esta verdad65.

Una conclusión para la novela que sin duda encajaba con la ortodoxia católica, cerrando el círculo de profesión cristiana del que hablamos con anterioridad. De nuevo aparecería la doctrina de San Agustín para recordarnos que somos peregrinos, es decir, extranjeros, en esta vida, porque el fin último siempre será volver a casa, a la patria, es decir, a la reunión con Dios.

Y cómo se atreverá el cristiano a alabarse de la pobreza que voluntariamente ha tomado para caminar en la peregrinación desta vida, más desembarazado por el camino que lleva a la patria, adonde las verdaderas riquezas es el mismo Dios ${ }^{66}$.

Así lo acabó entendiendo Gerardo y así podría explicarse. Vale.

\section{BiBLIOGRAFÍA}

Agustín, San, La ciudad de Dios, trad. Antonio de Roys y Roças, Madrid, Juan de la Cuesta, 1614.

Camamis, George, Estudios sobre el cautiverio en el Siglo de Oro, Madrid, Gredos, 1977.

Cervantes Saavedra, Miguel de, Don Quijote de la Mancha, dir. Francisco Rico, Barcelona, Crítica, 1998, 2 vols. 
Céspedes y Meneses, Gonzalo de, El español Gerardo y desengaño del amor lascivo. Discursos trágicos ejemplares, en Biblioteca de autores españoles. Tomo XVIII, Novelistas posteriores a Cervantes, Madrid, Atlas, 1946, pp. 117-271.

Céspedes y Meneses, Gonzalo de, Historias peregrinas y ejemplares, ed. Emilio Cotarelo, Madrid, Viuda de Rico, 1906.

Céspedes y Meneses, Gonzalo de, Historias peregrinas y ejemplares, ed. Yves René Fonquerne, Madrid, Castalia, 1969.

Céspedes y Meneses, Gonzalo de, Varia fortuna del soldado Píndaro, ed. Arsenio Pacheco, Madrid, Espasa-Calpe, 1975, 2 vols.

Claussen, M. A., «Peregrinatio and Peregrini in Augustine's City of God», Traditio, 46, 1991, pp. 33-75.

Covarrubias = Covarrubias, Sebastián de, Tesoro de la lengua castellana o española, ed. Felipe C. R. Maldonado, Madrid, Castalia, 1994.

Cucala Benítez, Lucía, «Céspedes y Meneses y la novela griega: la providencia en El español Gerardo y en Las etiópicas», Etiópicas, 2, 2006, pp. 335-362.

Cucala Benítez, Lucía, «Hacia una caracterización genérica de El Español Gerardo de Céspedes y Meneses. Entre la novela bizantina y la ficción sentimental», Anuario de Filología Hispánica, 13.1, 2010, pp. 49-65.

Fiordaliso, Giovanna, «Gonzalo de Céspedes y Meneses entre imitación y experimentación», Artifara, 13bis, 2013, pp. 97-116.

González-Barrera, Julián, «La novela bizantina española y la comedia La doncella Teodor de Lope de Vega. Primera aproximación hacia un nuevo subgénero dramático», Quaderni Ibero-americani, 97, 2005, pp. 76-93.

González-Barrera, Julián, «Soldados, doncellas y expósitos: Gonzalo de Céspedes y Meneses, un fiel lector cervantino», Nueva Revista de Filología Hispánica, 57.2, 2009, pp. 761-776.

González-Barrera, Julián, «Una deuda en Gonzalo de Céspedes y Meneses: la vitalidad del modelo bizantino en las Historias peregrinas y ejemplares», Revista de Filología Española, 90.2, 2010, pp. 233-256.

González-Barrera, Julián, Expostulatio Spongiae. Fuego cruzado en el nombre de Lope, Kassel, Edition Reichenberger, 2011.

González-Barrera, Julián, «Un capitán heresiarca en la biblioteca de Lope de Vega: Henricus Cornelius Agrippa», Revista de Filología Española, 98.2, 2018, pp. 319-340.

González Rovira, Javier, La novela bizantina de la Edad de Oro, Madrid, Gredos, 1996. 
Gracián, Baltasar, El discreto, en Obras completas, ed. Arturo del Hoyo, Madrid, Aguilar, 1967, pp. 73-147.

Gracián, Baltasar, El héroe. El político, ed. Agustín Izquierdo, Madrid, EDAF, 2009.

Hutchinson, Steven, «Literatura fronteriza mediterránea. Rasgos de un género literario», en Antes se agotan la mano y la pluma que su historia: Magis deficit manus et calamus quam eius historia. Homenaje a Carlos Alvar, ed. Constance Carta, Sarah Finci y Dora Mancheva, San Millán de la Cogolla, Cilengua, 2016, vol. II, pp. 1431-1450.

King, Willard F., Juan Ruiz de Alarcón, letrado y dramaturgo: su mundo mexicano y español, México, El Colegio de México, 1989.

Lionardi, Alessandro, Della inventione poética, Venecia, Plinio Pietrasanta, 1554.

López Enamorado, María Dolores, Larache a través de los textos. Un viaje por la literatura y la historia, Sevilla, Junta de Andalucía, 2004.

López Pinciano, Alonso, Philosophía antigua poética, en Obras completas, I, ed. José Rico Verdú, Madrid, Turner-Biblioteca Castro, 1998.

Madroñal, Abraham, «Sobre el autobiografismo en las novelas de Céspedes y Meneses a la luz de nuevos documentos», Criticón, 51, 1991, pp. 99-108.

Pittarello, Elide, «Sulle techniche narrative di El español Gerardo di Gonzalo de Céspedes y Meneses», Rassegna Iberistica, 8, 1980, pp. 3-46.

Riley, Edward C., «Don Quijote and the Imitation of Models», Bulletin of Hispanic Studies, 31, 1954, pp. 3-17.

Talens, Jenaro, «Contexto literario y real socializado. El problema del marco narrativo en la novela corta castellana del Seiscientos», en La escritura como teatralidad, Valencia, Universidad de Valencia, 1977, pp. 121-181.

Tasso, Torquato, Discorsi dell'arte poetica e del poema eroico, ed. Luigi Poma, Bari, G. Laterza \& Figli, 1964.

Tomás de Aquino, Santo, Suma de Teología, pres. Damian Byrne (O. P.), Madrid, Biblioteca de Autores Cristianos, 1988-1994, 5 vols.

Torquemada, Antonio de, Jardín de flores curiosas, ed. Giovanni Allegra, Madrid, Castalia, 1982.

Vega, Lope de, Comedias de Lope de Vega. Parte III, coord. Luigi Giuliani, Lérida, Milenio, 2002.

Vega, Lope de, Novelas a Marcia Leonarda, ed. Antonio Carreño, Madrid, Cátedra, 2002. 
Vilanova, Antonio, Erasmo y Cervantes, Barcelona, Lumen, 1989.

Wilkinson, Alexander S., y Ulla Lorenzo, Alejandra (eds.), Iberian Books: Books Published in Spain, Portugal and the New World or Elsewhere in Spanish or Portuguese between 1601 and 1650, Leiden / Boston, Brill, 2016, 2 vols.

Zimic, Stanislav, De esto y aquello en las obras de Cervantes, Newark, Juan de la Cuesta, 2010. 